\title{
Filter Cutoff Frequency
}

National Cancer Institute

\section{Source}

National Cancer Institute. Filter Cutoff Frequency. NCI Thesaurus. Code C94895.

Characteristic of a filter that gives the upper limit for the frequency content that essentially passes through it. 